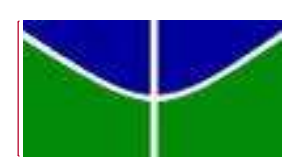

\author{
Universidade de Brasília \\ Instituto de Relações Internacionais \\ Programa de Pós-Graduação em Relações Internacionais \\ XX Curso de Especialização em Relações Internacionais
}

\title{
Países Desenvolvidos, suas práticas em comércio antes da consolidação de suas indústrias.
}

\section{Temístocles Lisandro Sena Loiola}

Artigo apresentado como requisito parcial para obtenção

do título de Especialista em Relações Internacionais pela Universidade de Brasília

Orientador: Prof. Dr. Alcides Costa Vaz

\author{
Brasília
}


RESUMO: Este texto apresenta um estudo qualitativo que visa resumir os principais argumentos do mercantilismo e do liberalismo e analisar as práticas de países desenvolvidos em relação ao comércio internacional antes de terem suas indústrias consolidadas. Para tal, parte-se do conceito de liberalismo e das atuações concretas dos países desenvolvidos que contradizem o que prega o pensamento liberal. A partir de uma revisão bibliográfica, o texto analisa as restrições adotadas em diferentes períodos por Grã-Bretanha e Estados Unidos com o objetivo de consolidarem suas indústrias antes da abertura comercial.

PALAVRAS-CHAVE: Liberalismo, Protecionismo, Indústrias, Comércio.

ABSTRACT: This paper presents a qualitative study that aims to summarize the main arguments of mercantilism and liberalism and analyze the practices of developed countries in relation to international trade before having their industries consolidated. To do so, it starts with the concept of liberalism and the concrete actions of developed countries that contradict what liberal thought preaches. From a bibliographical review, the text analyzes the restrictions adopted in different periods by Great Britain and the United States in order to consolidate their industries before comercial opening. KEYWORDS: Liberalism, Protectionism, discourse, practice, industries 


\section{INTRODUÇÃO}

Países em desenvolvimento hoje sofrem grande pressão por parte das nações mais desenvolvidas para adotarem uma série de boas práticas destinadas a promover maior liberalização do comércio internacional para assim atingirem o desenvolvimento econômico. Segundo esses países, "boas" são as políticas prescritas em Brettom-Woods e pelo Consenso de Washington e entre elas está a diminuição de barreiras ao comércio internacional. Mas questiona-se se esses países adotaram em seu passado as políticas que recomendam aos países em desenvolvimento, sobretudo em relação à liberalização do comércio internacional. Será que os países que hoje sugerem abertura comercial sempre foram de fato liberais? Esse estudo vem analisar a forma de atuação de países desenvolvidos em relação a abertura comercial quando ainda não possuíam indústrias consolidadas. Não faltam indícios ou evidências históricas sugerindo o oposto. Os Estados Unidos praticaram elevadas tarifas após a Guerra de Secessão e depois da Segunda Guerra Mundial, e quando sua supremacia industrial estava incontestável fizeram exatamente o mesmo que a Grã-Bretanha do século XIX fez, preconizou o livre comércio depois de ter protegido sua manufatura em períodos anteriores.

O objetivo deste artigo é analisar de que forma os países desenvolvidos (Grã-Bretanha, Estados Unidos) agiram durante o desenvolvimento de suas indústrias e trazer informações históricas que contradizem a visão que se propaga das políticas em comércio que esses países recomendam àqueles em desenvolvimento atualmente.

O momento a ser estudado focaliza o período entre o século XIII e o século XVIII, mais especificamente o período pós feudal quando a Grã-Bretanha até a revolução industrial, e o período que antecede a Guerra de Secessão nos Estados Unidos, além de outras experiências posteriores à Segunda Guerra Mundial.

A proposta de trabalho apresentada está em consonância com as perspectivas críticas das Relações Internacionais. Particularmente, a problematização teórica encontra boa aderência com a abordagem estruturalista que se ocupa de ponderar e explicar a manutenção das assimetrias no sistema mundo em que os países desenvolvidos almejam permanecer comprando matéria prima e 
vendendo produtos de maior valor agregado, sugerindo abertura comercial para seus produtos manufaturados, mas adotando políticas protecionistas à sua produção agrícola.

De acordo com o economista alemão Friedrich List (1789 - 1846) os países mais atrasados não conseguem desenvolver novas indústrias sem a intervenção do Estado, principalmente por meio de tarifas protecionistas apud (Chang, 2004). Sua obra principal, The National System of Political Economy, traz um exame de políticas comerciais e industriais dos países mais importantes do mundo ocidental e grande parte da exposição se opõe ao que se propaga sobre essas economias.

De acordo com Prebisch apud Jatobá (2013), os acordos comerciais para manutenção da divisão internacional de trabalho, onde um lado fornece matériaprima e produtos agrícolas, e o outro fornece manufaturado, reproduz as condições de subdesenvolvimento e das assimetrias entre as nações. Os teóricos Cardoso e Falleto (2005) apud Jatobá (2013), sustentam a ideia de que há uma estrutura na relação centro-periferia que perpetua a dependência dos países periféricos. Teotônio dos Santos apud Jatobá (2013), define dependência como a sujeição dos países periféricos à dinâmica capitalista dos países centrais e explica o subdesenvolvimento pela existência de uma estrutura capitalista global que drena as riquezas produzidas nos países periféricos em direção aos países centrais.

A importância do trabalho reside em discutir as recomendações sugeridas nos dias atuais para o comércio internacional e as adotadas anteriormente.

O trabalho seguirá a seguinte sequência: primeiramente, será apresentada uma síntese sobre a narrativa mercantilista; em seguida uma narrativa liberal na qual se encontram argumentos de defesa da indústria nacional; posteriormente serão analisados as ações adotadas pelos Estados Unidos e Grã-Bretanha antes de terem suas indústrias consolidadas. Após essa discussão, serão analisados os avanços e recomendações que ocorreram em termos de liberalização de comércio entre os países no âmbito do GATT e onde não houve avanço. 


\section{Matrizes teóricas}

\section{Pensamento Mercantilista}

Muitos historiadores afirmam que a disseminação do comércio foi a maior força de desintegração do feudalismo medieval. A expansão do comércio, particularmente aquele de longa distância levou ao estabelecimento de cidades comerciais que serviam de cenário para os negócios. (HUNT, 2002, pg.12) O comércio nessas cidades se tornou incompatível com os costumes feudais e as cidades obtiveram sucesso em ganhar independência da igreja e dos soberanos. (HUNT, 2002, pg 13).

A partir do século XVI o tipo de manufatura artesã, na qual o artesão possuía as ferramentas, o material, o local de venda, e funcionava de forma independente, foi substituído pela figura do mercador, que possuía o material, as ferramentas, o local de venda e passou a exportar. Nesse momento, os consumidores outrora locais, passaram a ser de lugares longínquos e a demandar em maior escala. Com o crescimento e desenvolvimento do comércio, a necessidade de mais produtos para atender a mercados distantes trouxe consigo a necessidade também de moeda que permitisse as negociações. (HUNT, 2002, pg 19)

Com a ascensão do comércio marítimo holandês e inglês, no século $\mathrm{XVI}$, a riqueza passou a migrar do sul da Europa para o norte. Nessa época começaram a surgir os Estados absolutistas e com eles a ideia da riqueza de nação, riqueza essa que se mediava pelo volume do tesouro (ouro e prata) que cada nação possuía. Dessa forma, a intervenção estatal seria de fundamental importância para a criação de um ambiente favorável para a acumulação de moeda a partir do comércio. Baseados no realismo político de Tucídides, Maquiavel e Hobbes, mercantilistas argumentavam que se as autoridades formais não perseguissem seus próprios interesses o resultado seria um brutal estado de natureza. (CRANE, 1991, pg 5)

Os mercantilistas acreditavam que o mundo possuía um "pote limitado de riqueza", de modo que, a riqueza de cada nação dependia de se garantir uma "balança comercial" favorável, na qual mais ouro deveria entrar no país do que sair, ou seja, o sistema era uma soma de resultado zero. Ao sair mais do que entrar, a prosperidade da nação diminuiria, cairiam os salários e perder-se-iam os empregos. 
Para os pensadores mercantilistas, a maximização do poder do estado e sua riqueza era a melhor maneira de se garantir o bem-estar público. (CRANE, 1991, pg 6)

$\mathrm{Na}$ concepção de John Locke, segundo Adam Smith em $A$ riqueza das nações, ouro e prata são as mais sólidas partes móveis da riqueza de uma nação, e multiplicar esses metais deveria ser o objetivo da economia política.

Segundo Hunt, no período mercantilista a concentração de capital estava com os mercadores, ou seja, o pouco capital industrial que ainda estava nas mãos dos artesãos, juntamente com os meios de produção, era relativamente menos importante que o capital dos comerciantes que detinham os meios de compra e venda, transporte e seguros.

Durante a primeira fase do mercantilismo, a Europa viveu um momento de falta de ouro e prata para a expansão do comércio. Neste período, chamado bulionista (sistema monetário conversível em ouro, prata ou metal precioso) foram desenhadas e implementadas pelos países europeus políticas para a atração de ouro e prata. Além disso, também foram adotadas políticas para o desestímulo à saída dos metais dos territórios dos países. As restrições adotadas para a diminuição do fluxo de saída de moeda permaneceram por um período que durou do final da idade média até o século XVII (HUNT, 2002, pg 21).

Embora liberal, ao explicar a importância da produção, Adam Smith exemplifica que o Império Romano não seria capaz de manter tropas distantes mandando ouro ou prata para os pelotões, mas mandando mantimentos. Dessa forma, a atividade produtiva vigorosa seria de maior importância que o próprio acúmulo de capital, ouro ou prata. (CRANE, 1991, pg 7 )

Após o período bulionista, o desejo de maximizar o fluxo de metais preciosos para dentro dos países ganhou o apoio dos governos para se criar uma balança comercial favorável que era ter um fluxo maior de entradas que de saídas de moedas. Dessa maneira, além da exportação de bens, incentivou-se a exportação de serviços como transporte e seguros. Segundo Hunt, uma das políticas mais eficazes de se garantir aumento de valor das exportações e diminuição do valor das importações foi a criação de monopólios de comércio. 
Em adição à criação de monopólios, todos os países da Europa ocidental (exceto Holanda) aplicaram extensivamente regulações às exportações e importações. Medidas destinadas a desencorajar as importações foram amplamente disseminadas. As importações de algumas commodities foram simplesmente proibidas por altas taxas que praticamente eliminaram o comércio delas. (HUNT, pg 22).

Outro tipo de restrição adotado à época foi a imposição de critérios de qualidade bastante severos para controlar a produção interna impondo a esta uma regulação de métodos de produção. (HUNT, 2002, pg 21)

Segundo Hunt não é exatamente claro o quanto o pensamento mercantilista desejava aumentar o poder do Estado ou aumentar os interesses dos mercadores. O que para os mercantilistas era irrelevante pois para eles a melhor maneira de promover os interesses do Estado era atender os interesses dos mercadores.

Embora temporalmente distantes do período áureo do mercantilismos, Alexander Hamilton e Friedrich List disseminam as ideias mercantilistas no século XVII e XVIII. A defesa da indústria nascente é o foco principal de seus argumentos contra o liberalismo.

Os primeiros argumentos sistematizados em prol da indústria nascente foram desenvolvidos por pensadores americanos como Alexander Hamilton e Daniel Raymond, ao passo que Friedrich List, o suposto pai intelectual da proteção à indústria nascente, entrou em contato com ela quando esteve exilado nos Estados Unidos. (CHANG, 2004, pg 110)

Nas palavras de Hamilton, primeiro Secretário do Tesouro dos Estados Unidos, "não apenas a riqueza, mas a independência e a segurança de um país estão materialmente conectadas com a prosperidade das manufaturas."

Como recomendações, em seus relatórios, Hamilton sugeria que fossem adotadas, tal qual como foram adotados por outros países: tarifas de proteção, proibição de importação de produtos rivais, proibição da exportação de materiais ou de indústrias, recompensas pecuniárias, premiações, exclusão de taxas sobre 
materiais ou manufaturas, devolução de taxas impostas a materiais para manufatura, incentivo a novas descobertas e invenções, entre outras. (CRANE, 1991, pg 44 - 45)

Um ponto que merece destaque por ser bastante semelhante com a prática adotada pela Grã-Bretanha no início da sua manufatura é a proibição da exportação de materiais. Nas palavras de Hamilton: "O desejo de assegurar uma oferta barata e abundante para os nacionais, e onde o produto é peculiar ao país, ou de qualidade peculiar, não capacitar trabalhadores estrangeiros para rivalizar com os da nação com seus próprios materiais, são os principais motivos para essa espécie de regulamentação."

O economista alemão Friedrich List (1789 -1846) considerado o pai do argumento da indústria nascente, afirma que em face dos países desenvolvidos, os mais atrasados não conseguem desenvolver novas indústrias sem a intervenção do Estado, principalmente por meio de tarifas protecionistas. (CHANG, 2004, pg 14). Em sua obra principal faz um grande exame das políticas comercial e industrial dos países mais importantes do mundo ocidental à época.

O novo mercantilismo, defendido por Friedrich List, se diferencia do antigo em três termos, substitui-se o acúmulo de metais preciosos por reservas externas, é muito mais preocupado com o desenvolvimento da indústria doméstica, isso significa maior proteção à indústria nascente e por último, do Estado é esperado maior intervenção na economia nacional. (Timothy, 2001, pg16)

List, diferentemente de Hamilton, não é inteiramente contra o livre comércio, ele afirma que o livre-comércio é benéfico entre países de nível semelhante de desenvolvimento industrial.

"Qualquer nação que, valendo-se de taxas protecionistas e restrições à navegação, tiver levado a sua capacidade industrial e sua navegação a um grau de desenvolvimento que impeça as outras de concorrerem livremente com ela não pode fazer coisa mais sábia que chutar a escada pela qual ascendeu à grandeza, pregar os benefícios do livre-comércio e declarar, em tom penitente, que até recentemente vinha trilhando o caminho errado, mas acaba de descobrir a grande verdade" (List, 1885, p. 295-6) 
A observação de List ficou plenamente confirmada quando, no século que se seguiu à publicação desses trechos, os Estados Unidos, não só se tornaram o mais ardente praticante - e o berço intelectual - do protecionismo, como, no fim do período passaram a ser o líder mundial da indústria. Os fatos históricos ulteriores deram razão a List também no tocante a "chutar a escada". Depois da Segunda Guerra Mundial, quando a sua supremacia industrial ficou absolutamente patente, os Estados Unidos fizeram exatamente a mesma coisa que a Grã-Bretanha do século XIX, preconizando o livre-comércio, muito embora tivessem obtido essa supremacia mediante o uso nacionalista e de um vigoroso protecionista. (CHANG, 2004, pg 18)

Paul Krugman em sua Nova Teoria de Comércio afirma que a proteção de uma indústria nascente através do mercado doméstico facilita a realização da economia de escala. $\mathrm{O}$ argumento é que um mercado interno protegido fornece a uma empresa uma vantagem de escala sobre produtos estrangeiros, e permite que ela eleve sua atuação em mercados estrangeiros, isso transfere lucros externos para fins domésticos e aumenta o bem estar interno em detrimento do externo. (Timothy, 2001)

O argumento contrário à proteção reside no fato de que impor barreiras ao fluxo de mercadorias aumenta o custo das mercadorias, isso afeta diretamente o consumidor. As barreiras podem gerar efeitos negativos sobre a economia do país, pois a proteção de uma indústria ineficiente diminui o bem-estar doméstico. De outra forma, o livre comércio traz vantagens ao consumidor na medida em que lhes dá acesso aos produtos com melhor preço. Analisaremos o pensamento liberal.

\section{O pensamento Liberal Clássico}

Liberais afirmam que o desenvolvimento econômico não pode ser alcançado enquanto interesses políticos suplantarem os interesses do mercado. Ainda, se os mercados funcionarem livremente, os interesses da maioria serão melhor atingidos. (CRANE, 1991, pg 55) 
Para Smith, a riqueza das nações não era a riqueza de cada nação individualmente, mas a riqueza de todas as nações, e para ele a riqueza não era limitada, como pensava Thomas Mun, ela poderia crescer com o tempo, condicionadamente à liberdade de comércio entre as diversas nações. Liberado o comércio a riqueza sempre cresceria para enriquecer todas as nações.

Para Adam Smith (1723-1790), como principal pensador liberal, contrário ao pensamento mercantilista, a riqueza não era meramente a quantidade de ouro e prata nos cofres do Estado, mas a riqueza proviria da capacidade produtiva de uma economia. (CRANE, 1991, pg 55). Smith visualizou que existiam interconexões entre as classes sociais, os variados setores de produção, a distribuição da riqueza, o comércio, a circulação de moeda, os processos de formação de preço e o crescimento econômico. (HUNT, pg 41).

Segundo Adam Smith existia a errada noção comum de riqueza, que seria a quantidade de ouro e prata guardada por um determinado país. "A rich country, in the same manner as a rich man, is supposed to be a country abounding in Money; and to heap up gold and silver in any country is supposed to be the readiest way to enrich it." Adam Smith, The wealth of nations.

Adam Smith exemplifica em A Riqueza das Nações que Espanha e Portugal, os proprietários das minas que supriam a Europa de metais, proibiram a saída de moedas sob penas severas, ainda assim, não conseguiam manter em seu território seus metais. Os mercadores consideraram essa proibição extremamente inconvenientes pois conseguiriam comprar com ouro e prata com maiores vantagens produtos do que com qualquer outro meio de troca. Dessa forma, a proibição era ineficaz.

Smith acreditava existirem quatro estágios de desenvolvimento social e econômico, podendo assim serem separadas as sociedades como: caçadoras, pastoris, agrícolas e comerciais, nessa ordem, da mais rude para a mais sofisticada. Para Smith, após o desenvolvimento da produção agrícola em um sistema de liberdade natural o capital seria direcionado para a manufatura. Descrevendo o fluxo de capital para a indústria doméstica sob um "sistema de liberdade natural", Smith formulou a base de sua tese afirmando que no livre mercado as ações egoístas 
individuais são orientadas diretamente por uma mão invisível de forma a maximizar o bem-estar econômico. A partir dessa premissa, Adam Smith conclui que intervenções governamentais, regulações, garantias de monopólio, subsídios, tudo isso redireciona o capital e diminui o bem-estar econômico. Como os governos não poderiam efetivamente gerenciar com sucesso as interações econômicas mundiais, uma nação colocada em um mercado não regulado deveria ser capaz de descobrir um nicho onde tivesse vantagem absoluta para conseguir produzir riqueza. (CRANE, 1991, pg 56).

Explicando o seu pensamento, Adam Smith afirmava que o país que não tivesse minas de metais preciosos precisava indubitavelmente conseguir seu ouro e prata de países estrangeiros, da mesma forma, se um país não tivesse vinícolas, deveria conseguir seu vinho de outros países. (Adam Smith, 1937) Segundo Smith, a regulação do mercado aconteceria de forma natural a depender da demanda onde a moeda fosse mais barata para onde fosse mais cara, de locais onde ela existisse em excesso para onde ela fosse escassa. Quando a quantidade de ouro e prata importados por algum país excedesse a sua demanda efetiva, nenhuma vigilância do Estado seria capaz de prevenir sua exportação.

A partir do pensamento de que uma nação em si é forte quando for capaz de manter um exército ou um destacamento em um território distante, Smith afirma que o destacamento ou o exército não consumira ouro ou prata, mas bens, portanto, um país com uma produção de bens poderia ser capaz de manter um destacamento distante por muito tempo, sem necessidade de metais preciosos.

Smith não era a favor do livre-comércio incondicionalmente. Existiam, em sua teoria, quatro situações que deveriam ser levadas em consideração. A primeira, o livre comércio deveria ser limitado pela segurança nacional, sendo ele simpático aos atos de navegação. Em segundo, tarifas deveriam ser impostas aos produtos importados da mesma forma que aos produtos nacionais para não haver vantagens indevidas aos produtos importados. A terceira situação, tarifas a produtos importados deveriam ser impostas como retaliação a restrições injustas praticadas em mercados externos, mas apenas para que elas fossem rescindidas. Finalmente, e a que chama maior atenção, o livre comércio deveria ser gradualmente ajustado de tal forma que 
a indústria doméstica e o emprego tenham tempo necessário para aumentar a concorrência internacional. (CRANE, 1991, pg 56)

David Ricardo incrementou ainda mais as ideias de Smith afirmando em sua teoria de vantagens comparativas que dois países poderiam se beneficiar do livre comércio mesmo que um dos parceiros fosse mais eficiente na produção de todos os bens. Ou seja, Ricardo argumenta que não era necessário haver vantagem absoluta para que o comércio internacional fosse benéfico para ambos os países. (HUNT, pg 120) No entanto, com o objetivo de acumular, várias medidas foram adotadas para limitar importações e aumentar exportações.

Pôde-se perceber que tanto os pensamentos mercantilistas e liberais possuem um ponto em comum que é a proteção à indústria nascente. Após a breve explanação sobre os pensamentos mercantilistas e liberais observaremos como dois principais defensores de liberalismo, Grã-Bretanha e Estados Unidos, atuaram em suas relações de comércio antes de terem uma indústria estabelecida. A GrãBretanha que era atrasada em termos de manufatura e comércio, a partir de políticas restritivas ao comércio desenvolveu amplamente a sua indústria.

\section{Grã-Bretanha}

Acredita-se que a Grã-Bretanha foi a primeira superpotência mundial graças à política do laissez-faire, enquanto a França teve a sua industrialização atrasada por conta de uma política intervencionista, no entanto, só depois de suas indústrias consolidadas, a Grã-Bretanha adotou a política liberal.

Reconhecidamente a fonte das doutrinas modernas do laissez-faire e considerada uma nação que se desenvolveu sem a intervenção significativa do Estado, a Grã-Bretanha utilizou-se de políticas restritivas ao comércio antes de ter sua economia manufatureira desenvolvida.

No período pós-feudal (séculos XIII a XIV) a Grã-Bretanha era uma economia relativamente atrasada. Sua exportação estava limitada à lã bruta e em 
menor escala ao tecido de lã com pouco valor agregado. Nesse período, os monarcas britânicos gravavam mais levemente o tecido que a lã bruta, e isso incentivou a substituição da importação de tecido de lã e favoreceu com algum sucesso a exportação desse produto. Apud (RAMSAY, 1982, p. 59)

Até 1600 a Grã-Bretanha importava grande parte do seu consumo do continente (Kindleberger, 1996, p.109). As exportações eram de lã bruta e tecido com pouco valor agregado para cidades mais adiantadas dos Países Baixos, Bruges, Ghen, e Ypres, em Flandres. Acredita-se que Eduardo III tenha sido o primeiro monarca a procurar desenvolver a manufatura local de tecido de lã, ele só usava roupa de tecido inglês, proibiu posteriormente a importação do tecido de lã. Apud Defoe (CHANG, 2004, p 36)

Os soberanos da dinastia Tudor deram novo ímpeto ao desenvolvimento da indústria com uma política que só pode ser descrita como de deliberado fomento à indústria nascente.(CHANG, 2004, p 39). Profundamente impressionado com a prosperidade dos Países Baixos, que se apoiavam na manufatura de lã, Henrique VII (1485 - 1509), adotou medidas de enviar missões para identificar lugares adequados para instalação de manufaturas, contratação de mão de obra especializada dos Países Baixos, aumento de tarifas e proibição temporária de exportação de lã bruta. Interessante destacar que já, naquele momento, determinavam que era preferível exportar pano semiacabado que lã bruta, e que era preferível exportar o pano tingido a exportar o pano bruto, revelando a preferência por exportações de produtos com maior valor agregado. Henrique VII só elevou a tarifa de exportação de lã bruta quando a indústria ficou mais consolidada. Tão logo se evidenciou que a GrãBretanha não tinha condições de processar toda a sua produção de lã, ele voltou a suspender os impostos e liberou a exportação. Apud (Defoe, 1728, p96)

Quase cem anos depois de Henrique VII ter dado início a sua política de substituição de importações, já no reinado de Elizabete I (1587) que a Grã-Bretanha ganhou suficiente confiança na competitividade internacional da sua manufatura e proibiu definitivamente a exportação de lã bruta, isso levou os fabricantes dos Países Baixos à ruína. (CHANG, 2004, p 41). 
No início do mercantilismo, a Europa se deparou com a falta de ouro e prata para a expansão do comércio. No período chamado bulionista medidas foram adotadas para a atração de metais preciosos e sua permanência nos países. Uma das primeiras políticas adotadas pela Grã-Bretanha para aumentar o valor das exportações e diminuir o valor das importações foi a criação de monopólios de comércio. Comerciantes ingleses poderiam comprar com preços mais baixos se apenas um comerciante barganhasse com estrangeiros, do que se muitos comerciantes ingleses comercializassem desordenadamente. Da mesma forma, a Inglaterra poderia auferir melhor lucro se apenas um comerciante negociasse a compra para todos os outros. (HUNT, 2002, pg 21)

Não apenas o uso de monopólios comerciais, mas a regulação ao comércio em exportações e importações foram adotados amplamente na Europa. Na Inglaterra isso ficou mais evidente pois os exportadores que não conseguiam competir com estrangeiros recebiam impostos de volta ou até mesmo eram subsidiados. A indústria têxtil Inglesa recebeu esse tipo de proteção. (HUNT, 2002, pg 22)

Entre 1651 e 1660 os atos de navegação "The English Navigation Acts" impuseram o uso de navios Ingleses tanto na importação, quanto na exportação de mercadorias que entrava ou saíam da Grã-Bretanha. Era uma maneira de aumentar o fluxo de moedas para dentro do país.

Entre os anos de 1700 e 1770, o mercado externo inglês cresceu mais rapidamente que a demanda doméstica. Esse crescimento rápido engatilhou a revolução industrial. (HUNT, 2002, pg 42). As cidades manufatureiras tiveram um enorme aumento de população, por exemplo, a população de Manchester era de 17.000 habitantes em 1760 e passou para 237.000 em 1831. Em 1801, 30\% da população inglesa trabalhava na indústria manufatureira, e em 1830 esse percentual passou a $40 \%$.

O sucesso industrial do laissez-faire britânico comprovou a superioridade das políticas de mercado livre e de livre comércio. Nesse período a Grã-Bretanha superou a França intervencionista, as duas principais potências da época, apoiada pelas ideias de Adam Smith que defendia que a ação individual de cada país com o objetivo de beneficiar-se a si mesmo geraria um resultado individual e global positivo. 
Robert Walpole, o primeiro premiê britânico, promoveu a reforma da legislação mercantil de 1721, Walpole declarou mediante a fala do trono ao Parlamento: "é evidente que nada contribui mais para promover o bem-estar público do que a exportação de bens manufaturados e a importação de matéria-prima estrangeira". A legislação aboliu tarifas alfandegárias das matérias-primas importadas pela manufatura, elevou-se o reembolso aduaneiro para as matérias primas importadas pelas manufaturas de exportação, compara-se a o que é hoje o Drawback. Aboliu-se o imposto de exportação da maior parte dos manufaturados, elevou-se a tarifa aduaneira de bens manufaturados importados, e foram estendidos subsídios à exportação a novos itens e aumentaram-se os subsídios aos produtos já exportados, e por fim, introduziram-se controles de qualidade dos produtos manufaturados para que produtores inescrupulosos não prejudicassem a imagem dos produtos britânicos no mercado externo.

Fica dessa forma claro que internamente as manufaturas eram protegidas contra a concorrência de produtos acabados estrangeiros e sempre que possível deviam-se oferecer incentivos na forma de isenções e subsídios.

Mesmo com a Revolução Industrial a Grã-Bretanha, embora tenha ampliado a sua liderança tecnológica sobre os outros países, não renunciou à política de fomento à indústria até meados do século XIX.

Indiscutivelmente a proteção tarifária foi a principal política de proteção utilizado pela Grã-Bretanha que perdurou até o fim da década de 1820. Proibições de importações também foram adotadas, o Wood Act, proibiu as exportações de produtos de lã provenientes das colônias. Em 1700 impôs barreira à importação dos produtos de algodão da Índia, de qualidade superior, e mais eficiente, em 1873 já se estimava que $40 \%$ a $45 \%$ da exportação têxtil de algodão da Grã Bretanha se destinava à Índia.

Gerard de Malynes (1586 -1641), perito inglês de comércio exterior, imaginava que a saída de ouro deveria ser restringida, pois se muito ouro saísse o valor da moeda inglesa cairia. Para Thomas Mun, um dos maiores teóricos mercantilistas, não existia nenhum problema em se comprar do exterior, desde que se comprassem produtos a serem utilizados na produção interna a ser exportada 
com valor mais alto, pois isso promoveria o comércio, propiciaria trabalho para o setor de transporte e aumentaria o estoque de capital inglês.

A Grã-Bretanha instituiu um vigoroso conjunto de políticas destinadas a impedir o desenvolvimento de manufaturas nas colônias, principalmente na América do Norte. (CHANG, 2002, pg 94). As políticas consistiam primeiro, no incentivo à produção de produtos primários nas colônias. Segundo, proibir algumas atividades manufatureiras nas colônias. Terceiro, proibir colônias de exportarem produtos que competiam com produtos britânicos. Quarto, autoridades coloniais foram proibidas de usar tarifas à importação. (Chang, pg 95 -96) Acreditava-se que o incentivo à produção de matéria-prima removeria as colônias de continuar desenvolvendo manufaturas que concorressem com as da Inglaterra. (CHANG, 2002, pg 95)

O Sistema mundial de livre comércio sucumbiu em 1932, quando a GrãBretanha até então sua ferrenha defensora, cedeu à tentação de reintroduzir tarifas alfandegárias. (CHANG, pg 31)

Após a análise feita das principais ações da Grã-Bretanha no sentido de consolidar suas indústrias, analisaremos uma outra nação que só adotou o discurso liberal após ter sua indústria fortalecida por ações de restrição ao comércio, os Estados Unidos.

\section{Estados Unidos da América}

Assim como a Grã-Bretanha, os Estados Unidos da América recorreram a práticas restritivas de comércio para desenvolver a sua manufatura. Muitos consideram que foi Alexander Hamilton, primeiro Secretário de Tesouro Americano, nos Reports of the Secretary of the Treasury on the subject of Manufactures (Relatórios do Secretário do Tesouro sobre a questão das manufaturas) o primeiro a elaborar sistematicamente argumento da indústria nascente. Nos Reports, Hamilton afirmava que a concorrência estrangeira impediria novas indústrias de se desenvolverem, a menos que a ajuda governamental compensasse os prejuízos iniciais. 
Desde os primórdios da colonização do que viria a ser os Estados Unidos da América, a proteção à indústria interna foi uma questão de política controversa. A Grã-Bretanha estava longe de querer industrializar as colônias e se encarregou de implementar políticas que impedissem a industrialização de suas colônias. Na época da independência, os interesses do Sul agrário se opunham ao protecionismo, enquanto os interesses das colônias do Norte, manufatureiras, o queriam.

Em A riqueza das nações, Adam Smith (1937, p.347-8) aconselha seriamente os norte-americanos a não caírem na tentação de promover sua indústria incipiente, os americanos rejeitaram essa análise com firmeza e passaram a proteger suas indústrias com grande sucesso a partir de 1816.

Inicialmente os Estados Unidos não tinham um sistema tarifário federal. Quando o congresso americano obteve o poder de tributar, aprovou em 1789 uma lei tarifária liberal, fixando uma tarifa única de $5 \%$ para todos os bens importados. (CHANG, 2004, pg 51)

Até a Guerra de 1812 com a Grã-Bretanha, o nível médio das tarifas ficou em torno dos $12,5 \%$, ao fim da guerra ou partir de então todas elas dobraram. O nível tarifário médio dos Estados Unidos estava próximo de 40\% em 1820. Em 1828, a chamada Tariff of Abominations dividiu o país, pois, na época, os agricultores do Norte e do Oeste estavam gravando muito as matérias primas e os bens manufaturados de pouco valor agregado que produziam, gerando tensão com os Estados manufatureiros da Nova Inglaterra (Apud Garraty \& Canes, 2000) Mesmo assim, em 1832, aprovou-se uma lei tarifária de $40 \%$ para os bens manufaturados redução muito abaixo das expectativas sulistas pois beneficiava somente os estados do norte.

Em 1833 foi aprovado um projeto de lei conciliador que embora oferecesse poucas reduções imediatas, previa uma redução paulatina, nos dez anos seguintes, para aproximadamente $25 \%$ para os bens manufaturados e $20 \%$ nos demais. Quando o período de dez anos expirou em 1842, aprovou-se uma nova lei, elevando as tarifas aos níveis praticados em 1832. (Apud Chang, pg 53) 
A lei de 1846 trouxe novamente uma redução do protecionismo, conquanto o imposto médio ad valorem sobre as 51 categorias mais importantes de bens importados continuasse sendo de $27 \%$. O período de 1846 a 1861 e considerado por Bairoch como de protecionismo moderado.

A tensão entre o Norte e o Sul, envolvendo tanto a questão tarifária quanto a do trabalho servil, persistiu e acabou desembocando na Guerra de Secessão (1861-1865)

Em 1864 elevaram-se mais uma vez as tarifas para atender às despesas de guerra, e continuaram em patamares elevados mesmo com o fim do conflito. Nesse sentido, a vitória do Norte, na Guerra de Secessão, permitiu aos Estados Unidos continuarem sendo os mais obstinados adeptos da proteção á indústria nascente até a $1^{\text {a }}$ Guerra Mundial, e mesmo até a segunda. (CHANG, 2004, pg 37)

Em 1913, em decorrência da vitória eleitoral dos democratas, aprovou-se o projeto de lei instituindo a Tarifa Underwood, que levou a "um grande aumento das categorias de bens com entrada livre e a uma queda substancial da média dos impostos de importação" (BAIROCH, 1993, p 37), mas a irrupção da Primeira Guerra Mundial tornou essa lei ineficaz.

Em 1922, em virtude do retorno dos republicanos ao poder, as tarifas receberam elevados índices, mas não comparáveis aos índices de 1861 -1913, ficando em torno de 30\% (CHANG, 2004, pg 37)

Em 1930, como o início da Grande Depressão, os Estados Unidos abandonaram o livre-comércio e instituíram a tarifa Smoot-Hawley, que colocou a alíquota média dos bens manufaturados em $48 \%$. Somente após a $2^{\mathrm{a}} \mathrm{Guerra}$ Mundial os Estados Unidos, com sua incontestável supremacia industrial, finalmente liberaram o comércio. (Apud Bhagwati, 1985, p.22 - Chang)

Bairoch (1993, p.51-2) salienta que, durante todo o século XIX até a década de 1920, a economia dos Estados Unidos foi a que mais rapidamente cresceu no mundo, conquanto tenha sido a mais protecionista em todo o período. No entanto, não há evidência de que a significativa redução do protecionismo da economia norte- 
americana, entre 1846 e 1861, tenha causado um impacto visivelmente positivo no desenvolvimento do país.

Após as Segunda Guerra Mundial, foram feitos progressos no que se refere à liberação do comércio, com o início das negociações do General Agreement on Trade and Tariffs (Gatt) - Acordo Geral sobre tarifas e Comércio. No entanto, a visão intervencionista dominou o cenário político do mundo desenvolvido até a década de 1970 e até a década de 1980 nos países em desenvolvimento, que para alguns autores como Sachs \& Warner (1995, p.11-21) uma teoria equivocada de indústria nascente retardou a abertura desses países.

Até então ficou clara que as ações adotadas por Estados Unidos e GrãBretanha antes de proporem o livre comércio não condizem com o pensamento liberal incondicional. Percebe-se no entanto que ambos possuem claros argumentos de defesa das indústrias nacionais até que elas sejam capazes de atuar no mercado internacional. As pressões que países desenvolvidos fazem em países em desenvolvimento para a liberalização de comércio fica evidente e formalizada a partir de Bretton Woods.

\section{O Sentido liberalizante do regime de Bretton Woods e o Consenso de Washington}

\section{Bretton Woods}

As origens da Organização Mundial do Comércio - OMC remontam ao final da Segunda Guerra Mundial e aos esforços dos aliados (União Soviética, Estados Unidos e Grã-Bretanha) em reconstruir a economia mundial. Em 1944, foi concluído um acordo, em Bretton Woods, EUA, com o objetivo de criar um ambiente de maior cooperação na área da economia internacional, baseado no estabelecimento de três instituições internacionais, o FMI, o Banco Mundia, e a OIC. (THORSTENSEN, 2001, pag 39)

A primeira, o FMI - Fundo Monetário Internacional, com o objetivo de manter a estabilidade das taxas de câmbio e assistir os países com problemas de 
balanço de pagamentos através de acesso a fundos especiais, e assim desestimular a prática da época de se utilizar restrições ao comércio cada vez que surgisse um desequilíbrio do balanço de pagamentos.

A segunda, o Banco Mundial ou Banco Internacional para a Reconstrução e Desenvolvimento, com função de fornecer os capitais necessários para a reconstrução dos países atingidos pela guerra.

A terceira seria a OIC - Organização Internacional do Comércio, com a função de coordenar e supervisionar a negociação de um novo regime para o comércio mundial baseado nos princípios do multilateralismo e do liberalismo.

Com o final da guerra, o FMI e o Banco Mundial foram criados, mas a OIC acabou por não ser estabelecida, uma vez que a Carta Havana, que delimitava seus objetivos e funções, nunca chegou a ser ratificada por um dos seus principais membros, os EUA. A carta não foi submetida ao Congresso dos EUA, porque na época, a maioria dos deputados temia que a nova instituição iria restringir a soberania do país na área do comércio internacional (THORSTENSEN, 2014, 39)

Aqueles que ocupavam posições de destaque na estrutura das finanças internacionais tiveram o poder de escrever as regras que definiriam o sistema, em termos que os colocavam em posição de vantagem. (TIMOTHY, 2014) Esse é o caso dos Estados Unidos que teve um papel fundamental na formação do sistema financeiro internacional após a segunda Guerra Mundial através do Sistema Bretton Woods. (TIMOTHY, 2014)

Nesse aspecto é importante reconhecer que uma vez criada uma estrutura todos os atores, do mais forte ao mais fraco, se tornam objeto do mesmo sistema de contenções e oportunidade. (TIMOTHY, 2014)

Em 1947, foi negociado um Acordo Provisório entre 23 países, que adotava apenas um segmento da Carta de Havana, aquela relativa às negociações de tarifas e regras de comércio. Este segmento era denominado Política Comercial (Capítulo IV) e passou a ser chamado General Agreement on Tariffs and Trade (Acordo Geral 
sobre Tarifas e Comércio) ou GATT. De simples acordo, o GATT se transformou, na prática, embora não legalmente, em um órgão internacional, com sede em Genebra, passando a fornecer a base institucional para diversas rodadas de negociações sobre comércio e a funcionar como coordenador e supervisor das regras do comércio até o final da Rodada Uruguai e a criação da atual OMC. (THORSTENSEN, 2001, p 73)

A Organização Mundial do Comércio - OMC, que passou a funcionar em 1995, tem como objetivo, formalmente, "a expansão da produção e do comércio de bens e serviços, a partir de uma proposta de desenvolvimento sustentável" (Prazeres, 2003. P 35) Buscava-se a liberalização do comércio, alcançando e fortalecendo a liberdade de iniciativa no âmbito internacional. (NASSER, 1999, p 48)

O sistema de regras do comércio internacional, como é hoje concebido, foi estabelecido ao longo dos anos através de rodadas de negociações multilaterais. As seis primeiras visaram basicamente a diminuição dos direitos aduaneiros, através de negociações de concessões de tarifas recíprocas. O sucesso dessas rodadas pode ser atestado quando se tem em conta que, em 1947, a média das tarifas aplicadas para bens era de $40 \%$ e que, em 1994, com a Rodada Uruguai, essa média caiu para $5 \%$.

Apesar do setor agrícola representar na época apenas $13 \%$ do comércio mundial, a forte pressão política dos agricultores dos países desenvolvidos que se posicionavam contra a redução dos apoios de seus governos ao setor, quase impediu o prosseguimento das negociações.

O setor agrícola deveria constar das regras do GATT, todavia, desde o seu início, o setor foi excluído através de derrogações ou exceções às obrigações do Acordo Geral. Os EUA objetivavam proteger seus mercados de importações e Europa estava em plena fase de implantação da sua PAC - Política Agrícola Comum. Ambos subsidiavam fortemente suas agriculturas.

Uma das críticas feitas ao Acordo e de que, na verdade, ele acabou legalizando, em nível de GATT, as políticas agrícolas protecionistas e subsidiadas 
dos países desenvolvidos principalmente Europa e EUA. (THORSTENSEN, 2001, pg 77)

Outro ponto negativo divulgados em trabalhos da UNCTAD e OMC sobre a rodada Uruguai, foi que o método de transformação de de medidas não tarifárias em tarifas ad valorem elevaram a margem de proteção a níveis elevadíssimos, praticamente impedindo a exportação de produtos agrícolas fora das quotas com tarifas reduzidas. Exemplos de tarifas com níveis de 250\% podem ser encontradas na EU, nos EUA, no Canadá e no Japão (UNCTADMTO, 1996) (Thorstensen, 2001, pg 77)

Barnett e Finnemore, no seu livro Rules for the World: International Organizations in World Politics (2004), afirma que organizações internacionais como o Fundo Monetário Internacional, se engaja em um irônico processo de disseminação de normas liberais pelo mundo. (TIMOTHY, 2014)

Kapoor (2004), por exemplo, afirma que a OMC atua primariamente como um veículo para forçar países e pessoas ao redor do mundo a práticas liberais, sem levar em conta a existência de uma democracia.

Os principais instrumentos de negociação após a Grande Depressão de 1929 e a Segunda Guerra Mundial o GATT e a OMC foram desenhados de forma a garantir maior fluxo de comércio, sem se importarem com o real desenvolvimento econômico dos países. Depois do recrudescimento das políticas protecionistas adotadas entre as décadas de 1960 e 1980 o Consenso de Washington foi um marco que formalizou recomendações liberalizantes aos países em desenvolvimento.

\section{O Consenso de Washington}

Exemplo claro da pressão que sofrem os países em desenvolvimento para abertura de seus mercados é o então chamado Consenso de Washington.

A história do Consenso de Washington data de 1989 quando a imprensa dos Estados Unidos ainda comentava a pouca disposição dos países da América 
Latina para realizar as reformas que Ihes permitiriam sair da crise. Para comprovarem, o Instituto de Economia Internacional decidiu convocar 10 nações latino-americanas para que detalhassem o que acontecia em seus países. Segundo John Williamson, criador do termo, em Resenha sobre o Consenso de Washington y sugestões sobre os passos a dar " para assegurar que todos abordassem um conjunto de questões em comum, redigi um documento de referências onde enumerei 10 reformas políticas econômicas que quase todos em Washington consideravam necessárias na América Latina naquele momento. $E$ a este programa nominei "Consenso de Washington"

O Consenso de Washington baseou-se nos seguintes 10 pilares: disciplina Fiscal, reorganização das prioridades do gasto público, reforma tributária, liberação das taxas de juros, câmbio competitivo, liberalização do comércio, liberalização do investimento estrangeiro direto, privatizações, e direito de propriedade.

Nas palavras do criador do termo, John Williamson "O acesso a importações de bens intermediários a preços competitivos é visto como uma importante forma de promoção, enquanto a política de proteção à indústria doméstica contra a competição externa é vista como uma criação de distorção que acaba penalizando exportações e empobrecendo a economia doméstica."

Portanto, o Consenso de Washington estimula a desregulamentação, o desmantelamento de políticas industriais, liberalização dos mercados via desregulamentação, privatizações da economia para um estado mínimo, e estabilização macroeconômica com política monetária restritiva com metas de inflação.

As políticas sugeridas pelo Consenso de Washington não estão permitindo à América Latina um crescimento sustentável e competitivo, isso se demonstra já que agora como economias abertas à globalização, o crescimento tem sido metade daquele alcançado na região entre as décadas de 1950-70, quando a região seguiu a estratégia de substituição de importações. (René Villareal) 
Como se pode apreciar, o Consenso de Washington sugeriu que os países atuassem menos em suas economias e liberassem o mercado, foram recomendações voltadas para países em desenvolvimento, no entanto não trouxeram nenhuma recomendação para os países desenvolvidos para abrir suas economias aos produtos dos países em desenvolvimento.

\section{Conclusão}

O comércio transfronteiriço envolve, minimamente, a presença de dois atores_com interesses e preocupações distintas, o que significa que livre comércio nunca é totalmente livre. Interesses governamentais e pressões de grupos de interesse sempre foram observados e levados em consideração, o que gera diferente formas de obstáculos ao comércio.

Desde uma perspectiva histórica, de fato, a posição padrão entre os estados soberanos tem sido uma posição mercantilista ou protecionista, em que diferentes tipos de barreiras ao comércio foram intencionalmente adotadas e para minimizar ou controlar as importações e, às vezes, até mesmo as exportações.

Sob o mercantilismo, manter uma balança comercial positiva (ou seja, uma situação em que o valor das exportações excede o valor das importações) é um objetivo primordial dos estados. Para alcançar isto, os governos nacionais tipicamente se engajaram em alguma forma de protecionismo.

O pensamento mercantilista, com a atuação clara de intervenção do Estado para o acúmulo de moedas, foi o primeiro a entender que a partir de uma atividade econômica seria simples o acúmulo de metal. Desenvolver a manufatura e o comércio, em não se possuindo minas de ouro e prata, era a forma de trazer para dentro do território as moedas que fariam a atividade econômica e industrial se desenvolver. O pensamento liberal, por sua vez, identifica as intervenções estatais como contraproducentes e desnecessárias, pois o mercado por si só seria capaz de se auto regular de forma a assegurar também ganhos de comércio. 
Após a Segunda Guerra Mundial os países que já estavam com suas indústrias consolidadas aproveitaram-se do momento para, na criação das organizações, e na elaboração de um novo sistema de comércio, disseminar as ideias liberais, sem contudo serem liberais nos produtos que os países em desenvolvimento conseguiriam competir.

O argumento da indústria nascente, que foi aludido amplamente, reflete princípios fundamentais da posição mercantilista ou neo-mercantilista, mas também encontra apoio nas posições liberais. Baseia-se na ideia de que os países industrializados tardiamente precisavam desenvolver sua capacidade industrial, para que não fossem permanentemente desfavorecidos na luta pela economia e pelo poder político internacional. A lógica do argumento é clara: no mundo, existem muitos países poderosos com economias bem desenvolvidas, indústrias competitivas, e forças militares - e existem países fracos militarmente e industrialmente atrasados"

Fato é que a indústria nascente é defendida pelo pensamento mercantilista e pelo pensamento liberal, e os países que preconizam hoje o livre comércio foram em momentos passados os maiores beneficiados por políticas protecionistas. Além disso, os países com economias mais avançadas tiveram uma vantagem decisiva sobre todos os outros. Isso porque suas indústrias eram mais desenvolvidas e economicamente competitivas. Como resultado, eles puderam facilmente dominar mercados ostensivamente livres ou abertos do comércio internacional. Contraditoriamente, os países de indústria consolidadas pregam o livre comércio, e não demonstram nenhum desconforto de praticar o protecionismo quando este se adapte aos seus propósitos.

As políticas concebidas no sistema Bretton Woods foram criadas e difundidas por países que já possuíam indústrias consolidadas, e almejavam abertura de mercados para seus produtos manufaturados mas ao mesmo tempo impõem barreiras aos produtos agrícolas de nações não desenvolvidas.

É de se destacar que as rodadas da OMC esbarraram nas medidas protecionistas dos países desenvolvidos, que mesmo hoje não abrem mão de subsidiar seus produtores rurais, e impõem barreiras tarifárias, ou fitossanitárias, ao comércio de produtos que protegem há bastante tempo. 
Os países desenvolvidos não seriam o que são hoje se tivessem adotado as políticas que recomendam. Eles adotaram práticas que agora repudiam como a proteção à indústria nascente e a prática de subsídios às exportações, que são condenáveis pela OMC.

As políticas sugeridas e disseminadas após Bretton Woods e sugeridas pelo Consenso de Washington como estratégias de desenvolvimento não foram adotadas pelos países desenvolvidos quando as suas indústrias ainda não possuíam o vigor necessário para competir internacionalmente em vez disso, políticas protecionistas foram adotadas.

Apesar das restrições ao comércio internacional, os países em desenvolvimento aumentaram sua participação no fluxo de comércio. No entanto, a participação desses países no comércio internacional não guarda correlação com a capacidade de agregar valor aos produtos. Em outras palavras, existe um fosso entre o valor agregado dos produtos fabricados e vendidos por países desenvolvidos e aqueles fabricados por países em desenvolvimento.

O hiato entre países desenvolvidos e aqueles em desenvolvimento no que concerne à capacidade de agregar valor aos seus produtos continua grande. Ou seja, os países desenvolvidos abriram mão de indústrias intensivas em mão de obra ou matéria prima para se especializarem em indústrias intensivas em capital e tecnologia. Dessa forma, fica claro que a teoria de Raúl Prebisch sobre a deterioração dos termos de intercâmbio ainda se sustenta, embora sob condições distintas das de sua formulação original. Os países desenvolvidos continuam vendendo produtos com maior valor e os países em desenvolvimento vendendo matérias primas, mas também manufaturas, mas de baixo valor agregado, ao mesmo tempo em que o protecionismo sob formas não tarifárias segue presente no repertório das políticas comerciais dos países desenvolvidos. 


\section{REFERÊNCIAS BIBLIOGRÁFICAS}

AMAWI, Abla. HF1359.T44 1991 -

BAIROCH, P. Economics and World History - Myths and Paradoxes. Brighton: Wheatsheaf, 1993

CHANG, Há-Joon, Chutando a escada: a estratégia do desenvolvimento em perspectiva histórica - São Paulo: Editora UNESP, 2004

CRANE, George T., 1957 -

HUNT, E. K. History of economic thought: a critical perspective 2nd updated ed.

HOSBSBAWM, E. A Era das Revoluções. Rio de Janeiro: Paz e Terra, 1977

JATOBÁ, D; LESSA, A. C; de OLIVEIRA, H. A. Teoria Das Relações Internacionais, São Paulo: Saraiva 2013.

PRAZERES, Tatiana Lacerda. Comércio Internacional e protecionismo: as barreiras técnicas na OMC. São Paulo: Aduaneiras, 2003).

THORSTENSEN, Vera. OMC - Organização Mundial do Comércio: as regras do comércio internacional e a nova rodada de negociações multilaterais 2 ed. São Paulo: Aduaneiras, 2001

TIMOTHY C. Lim, - International Political Economy - An Introduction to Approaches, Regimes, and Issues. 2014

NASSER, Rabih Ali. A liberalização do comércio internacional nas normas do GATTOMC. São Paulo:Ltr, 1999) 